\title{
Millisecond-delay Intervals in Horizontal Layering Bench Blasting Based on the Evaluation Model of the Entropy Weight Method
}

\author{
Yin Zuoming ${ }^{1}$, Wang Desheng, ${ }^{1, *}$, Zhang Xinghai ${ }^{3}$, Wang Xuguang² and Dang Zhiheng ${ }^{2}$ \\ ${ }^{1}$ Shool of Civil \& Resource Engineering, University of Science and Technology Beijing, Beijing 100083, China \\ ${ }^{2}$ Beijing General Research Institute of Mining \&Metallurgy, Beijing 100070, China \\ ${ }^{3}$ Zhengzhou Luneng Real Estate Co. LTD, Detroit, Henan 450000, China
}

Received 4 August 2020; Accepted 29 October 2020

\begin{abstract}
Millisecond-delay blasting in an open pit is difficult because the development of rock mass horizontal layering and mechanical properties vary widely among rocks. An unreasonable delay time for varied holes and rows often causes poor blasting effects. In this study, the multi-layer rock blasting model in the ANSYS/LS-DYNA software is used to optimize the delay time between holes and rows, improve the blasting effect, and reduce the vibration produced by blasting. The delay time for varied holes and rows is simulated. In line with the evaluation model of the entropy weight method, the maximum effective stress in the three sections is analyzed. The weight coefficient of each index is determined with entropy information theory, and a rock damage model is established. The ratio between the maximum tangential stress of the surrounding rock and the uniaxial compressive strength of the rock and the ratio of the uniaxial compressive strength of the rock to its tensile strength are selected as evaluation indicators. The maximum effective stress in the three sections at different positions between holes and rows is determined and analyzed. The test indicates that the delay time combination of 28 and $100 \mathrm{~ms}$ is effective and can avoid the interference of various geological conditions on the blasting effect. In accordance with the evaluation results, this delay time combination is used for field tests. Results demonstrate that the blasting effect of the selected delay time combination is remarkably enhanced, the boulder frequency is low, and the vibration caused by blasting is reduced by $30 \%$. In special geological conditions where the mechanical properties of rocks differ greatly, the evaluation model of the entropy weight method presents crucial advantages in the precise selection of millisecond-delay intervals for horizontal layering bench blasting.
\end{abstract}

Keywords: The entropy weight method, Digital electronic detonator, Explosive stress field, Millisecond-delay intervals

\section{Introduction}

With society's development, digital electronic detonators that can accurately delay time are now widely utilized in the industry; they provide new development opportunities for the technical innovation of open pit mines [1,2]. Blasting simulation of soft layered rock mass in different conditions has shown that changing the delay time can reduce or overcome the peeling of soft layered rock mass [3-7]. A reasonable millisecond delay time can improve the blasting quality of the open pit, reduce explosive consumption, improve the rock breaking rate, reduce blasting vibration, and increase economic benefits [8].

The choice of a reasonable delay time in milliseconddelay blasting entails different theoretical assumptions, such as increasing the free surface and reducing inter-rock compression [9]. The density of the rock and explosive, hole average charge, detonation velocity of explosives in the hole, propagation velocity and power of the shock wave, action mode of detonation gas, secondary wave action, and tensile wave action are physical and dynamic factors that affect the selection of delay time [10]. The majority of theoretical, semi-theoretical, and semi-empirical derivation methods are based on the factors that influence the selection of delay time, which do not fully represent the main factors [11]. Numerical simulation technology has developed rapidly, and

\footnotetext{
*E-mail address: wds812123@163.com

ISSN: 1791-2377 @ 2020 School of Science, IHU. All rights reserved.

doi:10.25103/iestr. 135.12
}

fruitful research has resulted in the usage of the finite element method and discrete element calculation method in obtaining reasonable delay time [12-17]. With regard to the widespread application of industrial digital electronic detonators, only few studies have focused on determining the reasonable delay time and evaluating the numerical simulation results under the conditions of the development of horizontal layering and complex mechanical properties of rock mass.

In this study, a finite element numerical calculation model is established for the horizontal layered rock mass of open-pit mines, and an evaluation model based on the entropy weight method is used to analyze and evaluate the stress state of key points on the slope and top. The method provides an effective, rapid, accurate solution for extracting the optimal delay time of millisecond-delay blasting under complex geological conditions from massive data. It improves the quality of millisecond-delay blasting, reduces explosive consumption, increases the rock breaking rate, reduces blasting vibration, and increases economic benefits.

\section{State of the art}

Scholars are constantly innovating drilling and blasting techniques to reduce explosive consumption, improve the rock breaking rate, and reduce blasting vibration [18-22]. The finite element method, discrete element method, finite 
element discrete element coupling method, similarity model experiment, fuzzy mathematical evaluation, and other technical means are widely used in theoretical studies on millisecond-delay blasting to increase the mining economic benefits when the development of rock mass horizontal layering and mechanical properties vary widely among rocks.

Zhou Jian et al. utilized discrete element numerical simulation technology to establish the rules of stress waves crossing fractures that show various attitudes [23]. Mohammad Reza Zareifard proposed a semi-analytical solution for the analysis of tunnels in consideration of the damaged zone. The solution was developed for circular tunnels excavated in rock mass that obeyed a new proposed nonlinear strain-softening behavior and the nonlinear HoekBrown failure criterion [24]. Jian Wang et al. compared the dynamic mechanical characteristics of a salt rock and mudstone interbed from Yingcheng. The scholars used the split Hopkinson pressure bar (SHPB) apparatus under triaxial confining pressure. The formula for the dynamic strength of the salt rock and mudstone interbed was derived by data fitting with a simplified strength-strain rate model on the competition between the mechanisms of thermal activation and macroviscosity. [25]. Shi Xiaopeng and $\mathrm{Wu}$ Chunping et al. analyzed the rock breaking and vibration reducing mechanisms of millisecond delay blasting [26]. To solve blasting vibration problems in a lead-zinc mine, a large amount of monitoring data was obtained through field tests, and the interval time of mine blasting was confirmed through data analysis. The results of the study showed that an interval time of $50 \mathrm{~ms}$ staggers the peak superposition of blasting vibration, thus achieving vibration reduction. The results of the study also provide a theoretical basis and technical support for control blasting vibration of lead-zinc mines. Chen Hui et al. studied two kinds of blasting charge structures of layered rock mass in Heishan Coal Mine in Xinjiang through a theoretical analysis of the charge structure, an LS-DYNA 3D numerical simulation experiment, and a field industrial test. The results showed that the air-deck charge of layered rock mass is better than the column charge, which improves the effective energy utilization rate of blasting. Good results were achieved in terms of the blasting process, fragmentation effect, root residue conditions, and back-tension range; these results have helped improve the efficiency of excavation operations and reduce mining costs [27].

Meanwhile, Song Quanjie et al. established the attenuation laws of blasting vibration in different directions to stratification during the process of blasting excavation on the basis of the monitoring point velocity of blasting vibration [28]. A.K. Raina et al. defined and determined the impulse pressure and time to make the application of flyrock prediction equations highly scientific [29]. Binay Kumar Singh et al. evaluated and analyzed blasting delay time, borehole depth, charging structure, and other influencing factors through digital image analysis to reduce the bulk rate and improve the blasting effect [30]. Zhong Dongwang et al. obtained a precise time delay by using a digital electronic detonator based on energy distribution theory of explosive charge in rock mass and calculated the reasonable delay time interval between blasting holes; the effectiveness of the approach was proven by production practice [31]. K. Iwano et al. reproduced the vibration waveforms in delay blasting from a seed waveform recorded in single-shot blasting. The optimum delay interval determined accurately from the superposition method was nearly equal to the one simply estimated from the method with the autocorrelation coefficient or frequency analysis of the vibration waveform in single-shot blasting [32]. Hamid Reza Mohammadi Azizabadi et al. simulated the surface vibration generated by blasting in the stability assessment of the rock slope of an open-pit mine through the vibration measurement data on a single blasting hole. The simulated production blast seismograms were then adopted as an input to predict the time histories of particle velocity in blast vibrations on the mine wall by using the universal distinct element code (UDEC). The simulated time histories of particle velocity showed good agreement with the measured data[33]. Navarro Torres V.F. et al. collected data that were processed with multiple regression techniques to obtain the blasting vibration attenuation law and predict the levels of blasting-induced vibrations for the locality under study. They had knowledge of only the maximum explosive charge per delay and the distance to the blasting point. Brazilian and international admissibility standards of blasting-induced vibration, the minimum distance between the mine and community, and the constants obtained from the regression were used to establish the maximum explosive charge per delay for an acceptable ground vibration level that would not cause structural damage and human discomfort [34]. Jianguang Xue et al. established an attribute recognition model of assessment for the classification of rock mass stability in engineering blasting based on attribute mathematical theory. The aim was to overcome the subjective and erroneous tendency problem of the expert determination method in the assessment of the classification for rock mass stability [35]. Considering the key influencing factors of rock burst comprehensively, Wang Yingchao et al. established a model for predicting and classifying rock bursts based on the ideal point method. The prediction results were in good agreement with the practical situation of rock bursts, and the prediction model was proven to be reliable [36].

Generally, most of these results are for the optimization of blasting schemes under general working conditions. In view of special geological conditions where the horizontal layering of the rock mass is developed and the rock mechanical properties vary greatly, study on the application of digital electronic detonators is minimal, and accurate analysis and investigation of the optimal delay time are lacking.

In the current study, the stress states of different positions between rows and holes are studied, and the rock damage characteristics under special geological conditions involving developed horizontal layering and large differences in rock mechanical properties are discussed using finite element numerical simulation calculation and entropy weight methods. The outcome is applied to the optimal delay time in horizontal step blasting holes of 1105 $\mathrm{m}$ in Heidaigou Open-pit Mine. An evaluation model of entropy weight for the delay time selection of digital electronic detonators is established to provide a basis for the optimization of the blasting scheme and field test and expand the research method of millisecond blasting theory.

The remainder of this study is organized as follows. Section 3 describes the layered rock structure and blasting scale and establishes a finite element calculation model of Heidaigou Open-pit Mine. Section 4 presents the use of information entropy theory to determine the weight coefficients of each index, the establishment of a model of rock damage, the analysis of the maximum effective stress in three cross-sections at different positions between the holes and rows, the obtainment of the best delay time, and the 
verification of the field tests. Section 5 summarizes the conclusions.

\section{Methodology}

Heidaigou Open pit Mine is one of largest output single well which is located in central Inner Mongolia in China. The blasting effect is not ideal due to the different horizontal layering development and mechanical properties of the overlying rock mass, and the unreasonable delay time of different holes and rows. On the $1105 \mathrm{~m}$ horizontal loosening blasting sites in the Heidaigou Open pit Mine, the upper rock model is a mud-stone model and is $3 \mathrm{~m}$ thick. The middle layer is a clay-rock model and is $3 \mathrm{~m}$ thick. The lower layer is a sandstone model. The combination of delay time between different holes and rows is studied by numerical simulation.

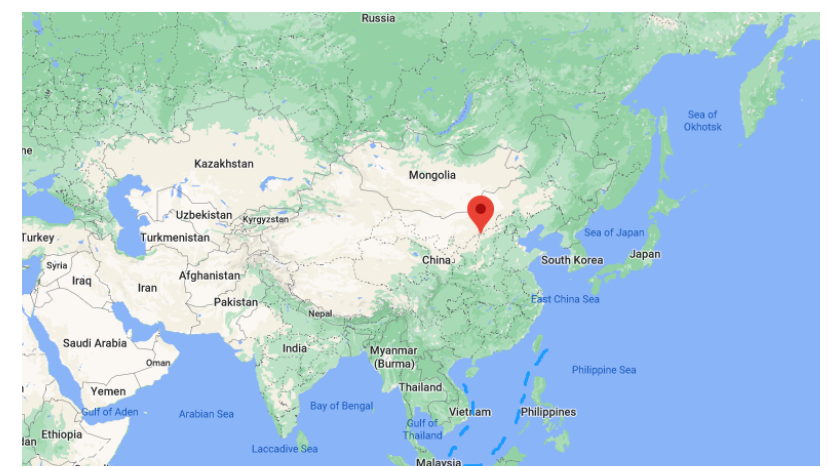

Fig. 1. Location of Hei Daigou Open-pit Mine in China

\subsection{Selection of model, materials, and parameters}

There are many methods to accurately describe the pressure change process during charge detonation in numerical simulation. The basic principle is to describe the dynamic expansion of the entire detonation chamber by combining the detonation research results of explosives with the state equation of detonation gas. Ls-dyna program can directly simulate the detonation process of high-energy explosives. At any moment, the explosive pressure on the surrounding rock is as follows:

$$
\begin{aligned}
& P=F P_{e o s}(V, E) \\
& F=\left\{\begin{array}{cc}
\frac{2\left(t-t_{1}\right) D A_{e \max }}{3 v_{e}} & \left(\mathrm{t}>t_{1}\right) \\
0 & \left(\mathrm{t} \leq t_{1}\right)
\end{array}\right.
\end{aligned}
$$

Where $P$ is the explosion pressure, $F$ is the chemical energy release rate of the explosive, $V$ is the explosive detonation velocity, $t$ and $t_{1}$ are the initiation time of the current time and the initiation time inside the explosive, $A_{\text {e } \max }$ is the maximum cross-sectional area of the explosive unit, $v_{\mathrm{e}}$ is the unit volume of explosive.

In this study, the ANSYS/LS-DYNA software is employed to simulate the blasting process of explosives in rocks. High-performance explosive model (*MAT_HIGH_EXPLOSIVE_BURN) and JWL equation are adopted to simulate blasting process. The parameters of ammonium oil explosives and JWL equation are shown in Table. 1.

$$
P_{\mathrm{eos}}=A\left(1-\frac{\omega}{R_{1} V}\right) e^{-R_{1} V}+B\left(1-\frac{\omega}{R_{2} V}\right) e^{-R_{2} V}+\frac{\omega E_{0}}{V}
$$

Where $P_{\text {eos }}$ is the pressure determined by JWL equation of state, $V$ is the relative volume, $E_{0}$ is the initial specific internal energy, $A, B, R_{1}, R_{2}$, and $\omega$ are five independent physical constants describing JWL equation.

Table 1. The parameters of ANFO and JWL equation

\begin{tabular}{c|c|c|c|c|c|c|c}
\hline \multicolumn{2}{c|}{ ANFO } & \multicolumn{7}{c}{ State equation } \\
\hline $\begin{array}{c}\text { Density/ } \\
\left(\mathrm{g} / \mathrm{cm}^{3}\right)\end{array}$ & $\begin{array}{c}\text { Detonation } \\
\text { velocity/(m/s) }\end{array}$ & $\begin{array}{c}\mathrm{A} \\
/ \mathrm{GPa}\end{array}$ & $\begin{array}{c}\mathrm{B} \\
/ \mathrm{GPa}\end{array}$ & $R_{1}$ & $R_{2}$ & $\omega$ & $\begin{array}{c}E_{0} \\
/ \mathrm{GPa}\end{array}$ \\
\hline 0.86 & 2862 & 374 & 18 & 4.2 & 0.9 & 0.3 & 3.6 \\
\hline
\end{tabular}

The parameters of the air model (*MAT_NULL) and the state equation (*EOS_LINEAR_POLYNOMIAL) are shown in Table. 2. The density of air is $1.225 \mathrm{~kg} / \mathrm{m}^{3}$. The pressure is simulated by a linear polynomial equation of state ${ }^{*} \mathrm{EOS}-$ LINEAR-POLYNOMMIAL). The equation is expressed as follows:

$$
\begin{aligned}
& P_{\text {poly }}=C_{0}+C_{1} \mu+C_{2} \mu^{2}+C_{3} \mu^{3}+\left(C_{4}+C_{5} \mu+C_{6} \mu^{2}\right) E \\
& \mu=1 / V-1
\end{aligned}
$$

Where $C_{0} \sim C_{6}$ are constant, $\mu$ is volume ratio, and $E$ is the ratio of internal energy to initial volume.

Table 2. The parameters of the air model and the state equation

\begin{tabular}{c|c|c|c|c|c|c|c}
\hline Parameter & $\rho_{0}$ & $E_{0}$ & $v_{o}$ & $C_{0} \sim C_{3}$ & $C_{4}$ & $C_{5}$ & $C_{6}$ \\
\hline Value & 1.225 & $2.5 \mathrm{E} 5$ & 1.0 & 0 & 0.4 & 0.4 & 0 \\
\hline
\end{tabular}

The plastic model (*MAT_PLASTIC_KINEMATIC) is adopted for rock and blockage. The Eulerian algorithm is used for the explosive models, air models, and blockage material models. The Lagrange algorithm is applied to rock model. If the fluid-structure interaction algorithm is applied, there will be no element distortion. With such an advantage, the algorithm has been widely used in the engineering numerical simulation that has large deformation and high strain rate. Hence, the multi-material fluid-structure interaction algorithm can be applied to deal with the interaction process of detonation products and surrounding rock media. The maximum unit side length in the divided model mesh is $0.25 \mathrm{~m}$, and the parts around blast holes are encrypted.

On the $1105 \mathrm{~m}$ horizontal loosening blasting sites in the Heidaigou open-pit mine, the upper rock model is a mudstone model and is $3 \mathrm{~m}$ thick. The middle layer is a clay-rock model and is $3 \mathrm{~m}$ thick. The lower layer is a sandstone model. The mechanical properties are shown in Table. 3.

Table 3. Rock parameters

\begin{tabular}{c|c|c|c|c|c}
\hline Type & $\begin{array}{c}\text { Bulk } \\
\text { density } \\
/\left(\mathrm{g} / \mathrm{cm}^{3}\right)\end{array}$ & $\begin{array}{c}\text { Compressive } \\
\text { strength } \\
/ \mathbf{M P a}\end{array}$ & $\begin{array}{c}\text { Shear } \\
\text { strength } \\
/ \mathbf{M P a}\end{array}$ & $\begin{array}{c}\text { Elastic } \\
\text { modulus } \\
/ \mathbf{G P a}\end{array}$ & $\begin{array}{c}\text { Poisson's } \\
\text { ratio }\end{array}$ \\
\hline $\begin{array}{c}\text { Mud } \\
\text { stone }\end{array}$ & 2.27 & 41.39 & 17.08 & 2.45 & 0.27 \\
$\begin{array}{c}\text { Clay } \\
\text { rock }\end{array}$ & 1.73 & 24.56 & 2.73 & 3.56 & 0.25 \\
$\begin{array}{c}\text { Sand } \\
\text { stone }\end{array}$ & 2.18 & 29.65 & 24.52 & 4.09 & 0.24 \\
\hline
\end{tabular}




\subsection{Establishment of multi-layer rock model}

Based on the on-site geological conditions, a three-hole bench blasting model of the multi-layer lithologic medium is established. As shown in Fig. 2, the model is $29.5 \mathrm{~m}$ long, $20.5 \mathrm{~m}$ wide and $23 \mathrm{~m}$ high. Specifically, the bench slope is 80 degrees. The bench is $15 \mathrm{~m}$ high. Distance from the bench bottom to the model bottom is $8 \mathrm{~m}$. The blast-hole diameter is $250 \mathrm{~mm}$. The slope-bottom resistance line is 6.5 $\mathrm{m}$. Distance from the front blast-hole to heading face is $4 \mathrm{~m}$. The spacing between holes is $15 \mathrm{~m}$. The spacing between rows is $5.5 \mathrm{~m}$.

The 3D-SOLID164 physical unit is selected for the bench model. The front and back model surfaces are defined as a symmetrical boundary. The left, right and bottom model surfaces are defined as free boundaries, and the bench top, slope and other surfaces contacting with air are defined as non-reflective boundaries. The ANSYS/LS-DYNA software has no requirements on units, so the model adopts the international units of $\mathrm{m}, \mathrm{kg}$ and $\mathrm{s}$.

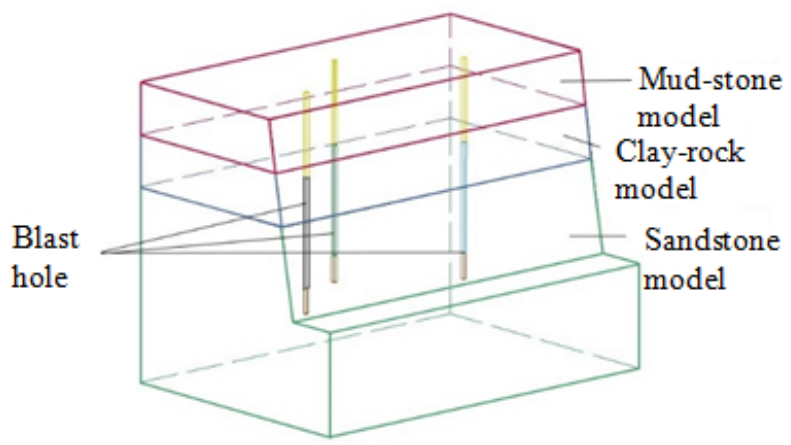

Fig. 2. Schematic diagram of step model with large density coefficient

As shown in Fig. 3 , the maximum effective stress of 188 monitoring points in three model sections is selected for analysis. Section 1-1 demonstrates the monitoring points on various rock formations between the front two blast-holes. Sections 2-2 and 3-3 display the positions of the blast-hole 2 and 3 that are perpendicular to bench detection points.

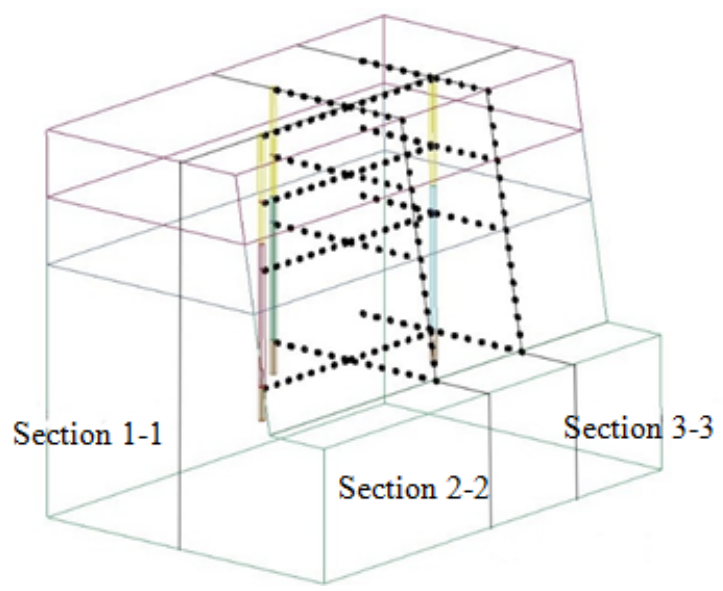

Fig. 3. Location of monitoring points

\subsection{Determination of denotation time for varied blast- holes}

According to the empirical equation concluded by the Research Institute of Mining and Metallurgy on sand rocks, the reasonable and calculated delay time for holes is from 20 $\mathrm{ms}$ to $73 \mathrm{~ms}$ [26]. The delay time for rows is from $63 \mathrm{~ms}$ to
$157 \mathrm{~ms}$. The selected time interval is $5 \mathrm{~ms}$. To avoid the parallel situation, the delay time for holes includes 10 working conditions, such as $18 \mathrm{~ms}, 23 \mathrm{~ms}, 28 \mathrm{~ms}, \ldots 63 \mathrm{~ms}$. The delay time for rows contains 18 conditions, including 18 $\mathrm{ms}, 70 \mathrm{~ms}, 75 \mathrm{~ms}, \ldots 150 \mathrm{~ms}$. A total of 180 delay time combinations for holes can be matched.

\section{Result Analysis and Discussion}

In line with the evaluation model of the entropy-weight method, the maximum effective stress on the three sections is analyzed. The weight coefficient of each index is determined by entropy-information theory, and the rock damage model is established. The ratio between the maximum tangential stress of surrounding rock and the uniaxial compressive strength of rock, ratio of uniaxial compressive strength to the tensile strength of rock, are selected as indicators of evaluation. The maximum effective stress of three sections at different positions between holes and rows was screened and analyzed.

\subsection{Establishment of the Evaluation Model of Entropy- eight Method}

The effective stress matrix $R\left(r_{i j}\right)$ relative to the maximum effective stress at varied monitoring points and the dynamic tensile strength among rocks is established, which $r_{i j}$ represents the relationship between the maximum effective stress at varied monitoring points and the dynamic tensile strength among rocks. When the maximum effective stress $\sigma$ at varied monitoring points exceeds the dynamic tensile strength among rocks, the rocks at monitoring points can be blasted. $r_{i j}$ refer to the difference value. Otherwise, the rocks at monitoring points cannot be blasted and the effective stress matrix $r_{i j}$ becomes 0 . The effective stress matrix is as follows:

$r_{i j}(\sigma)=\left\{\begin{array}{cc}\sigma_{i j}-\sigma_{b} & \sigma_{i j}>\sigma_{b} \\ 0 & \sigma_{i j} \leq \sigma_{b}\end{array}\right.$

Where $r_{i j}$ represents the effective stress at the $j$ monitoring point under the $i$ working condition of delay time combination.

An evaluation model $Q$ is established to demonstrate the value that the weight value $\beta$ multiplies the effective stress matrix $R\left(r_{i j}\right)$ at each monitoring point. When the obtained model value turns larger, the effective stress becomes stronger and the change becomes smaller, which is more conducive to rock blasting. The evaluation model of the $i$ delay time combination is as follows:

$$
Q_{i}=\sum_{j=1}^{n} w_{j} \times r_{i j}
$$

The calculation results of the evaluation model $Q$ are conformed to the five-level evaluation principle progressively. As shown in Table. 4, the calculation results of each section evaluation model $Q$ are qualitatively evaluated. The worse evaluation results on the three sections are selected as the numerically simulated the evaluation results of the delay time combination. 
Table 4. Classification of evaluation indexes

\begin{tabular}{|c|c|c|c|c|c|}
\hline $\begin{array}{l}\text { The } \\
\text { evaluation } \\
\text { model } Q\end{array}$ & $\begin{array}{l}< \\
0.01\end{array}$ & $0.01 \sim 0.02$ & $0.02 \sim 0.03$ & $0.03 \sim 0.04$ & $\begin{array}{l}> \\
0.04\end{array}$ \\
\hline $\begin{array}{l}\text { Evaluation } \\
\text { of blasting } \\
\text { effect }\end{array}$ & Worst & Poor & Middle & Better & Best \\
\hline
\end{tabular}

\subsection{Calculation of weight value}

Based on relevant studies, when the effective stress at a monitoring point is evaluated, the smaller the difference, the uniform the effective stress. When the influence of varied delay time combinations on the effective stress is small, the entropy value becomes larger. It demonstrates that the index weight value is small. Otherwise, it means that the index weight value is large. Through the entropy-weight method, the weight value of the effective stress at various monitoring points that impacts the blasting effect is calculated.

The data normalization is to eliminate the impact generated from the large difference of the effective stress at various monitoring points. The effective stress data matrix $R\left(r_{i j}\right)$ is required to be normalized, and the obtained matrix after normalization is $B\left(b_{i j}\right)$.

$$
b_{i j}=\frac{r_{i j}}{\max \left\{r_{i j}\right\}}
$$

The calculation of entropy value is as follows. The entropy value of the effective stress at the monitoring point is

$$
h_{j}=-k \sum_{i=1}^{n} f_{i j} \ln f_{i j}
$$

$$
f_{i j}=\frac{b_{i j}}{\sum_{i=1}^{n} b_{i j}}
$$

The formula $f_{i j}$ represents the index weight standardized value of the effective stress at the $j$ monitoring point under the $i$ delay time combination.

$k=\frac{1}{\ln n}$

Where $k$ represents the adjustment coefficient of $n$ delay time combinations to the entropy value.

The calculation of entropy-weight value is as follows. The entropy-weight of the effective stress at the $j$ monitoring point is

$$
w_{j}=\frac{1-h_{j}}{m-\sum_{j=1}^{m} h_{j}}
$$

Specifically,

$$
\sum_{j=1}^{m} W_{j}=1, W_{j} \in(0,1)
$$

\subsection{Application of evaluation model of entropy-weight method}

Various delay time combinations have diverse effects on blasting effects. The simulated results about the maximum effective stress at varied monitoring points on the sections are analyzed. The matric calculation through the MATLAB software has been made. Connected with the classified

\begin{tabular}{|c|c|c|c|c|c|c|c|c|c|}
\hline \multirow[t]{2}{*}{ Number } & \multicolumn{2}{|c|}{$\begin{array}{c}\text { Delay time } \\
\text { combination/(mm) }\end{array}$} & \multicolumn{2}{|c|}{ Section 1-1 } & \multicolumn{2}{|c|}{ Section 2-2 } & \multicolumn{2}{|c|}{ Section 3-3 } & \multirow{2}{*}{$\begin{array}{l}\text { Evaluation } \\
\text { result }\end{array}$} \\
\hline & Hole & Row & Calculation & Evaluation & Calculation & Evaluation & Calculation & Evaluation & \\
\hline 1 & 18 & 65 & 0.0353 & Middle & 0.0252 & Poor & 0.0322 & Middle & Poor \\
\hline 2 & 18 & 70 & 0.0385 & Middle & 0.0298 & Poor & 0.0383 & Middle & Poor \\
\hline 3 & 18 & 75 & 0.0490 & Better & 0.0260 & Poor & 0.0267 & Poor & Poor \\
\hline$\vdots$ & $\vdots$ & $\vdots$ & $\vdots$ & $\vdots$ & $\vdots$ & : & $\vdots$ & $\vdots$ & . \\
\hline 8 & 18 & 100 & 0.0507 & Best & 0.0555 & Best & 0.0946 & Best & Best \\
\hline : & : & : & : & : & : & : & : & : & : \\
\hline 44 & 28 & 100 & 0.0521 & Best & 0.0552 & Best & 0.0581 & Better & Better \\
\hline$\vdots$ & $\vdots$ & : & $\vdots$ & $\vdots$ & : & $\vdots$ & : & : & - \\
\hline 178 & 63 & 140 & 0.0410 & Better & 0.0321 & Middle & 0.0291 & Poor & Poor \\
\hline 179 & 63 & 145 & 0.0345 & Middle & 0.0326 & Middle & 0.0375 & Middle & Middle \\
\hline 180 & 63 & 150 & 0.0304 & Middle & 0.0204 & Poor & 0.0240 & Poor & Poor \\
\hline
\end{tabular}
evaluation indexes shown in Table. 5, the delay time combinations at three sections that are feasible for rock blasting are selected for field tests.

Table 5. simulation results of different delay time combinations

Based on the evaluation of numerical simulation results on 180 delay time combinations, $31 \%$ of evaluation results show that the effect is medium or more. Specifically, the evaluation result for the $18 \mathrm{~ms}-100 \mathrm{~ms}$ delay time combination is good. Comparatively, the evaluation result for the $28 \mathrm{~ms}-100 \mathrm{~ms}$ delay time combination is fairly good. The digital electronic detonator is adopted to conduct on-site tests for the above two delay time combinations. The delay time for production and application in the mining area is determined through the observation of blasting effects.

\subsection{Field test of digital electronic detonator blasting design}

The test site is located in the south of the $1105 \mathrm{~m}$ horizontal mining area. Through the GPS measurement, it is known that the test site has a flat blasting area, which covers an area of $9725.29 \mathrm{~m}^{2}$. Its average bench height is $15.5 \mathrm{~m}$, and its 
rock blasting volume is $150,700 \mathrm{~m}^{3}$. The triangle drilling way is arranged with a hole spacing of $5.5 \mathrm{~m}$, a row spacing of $15 \mathrm{~m}$, and a hole depth of 17-18 $\mathrm{m}$. The sketch diagrams of rock layering and loading structure are shown in Fig. 4 and Fig. 5 respectively.

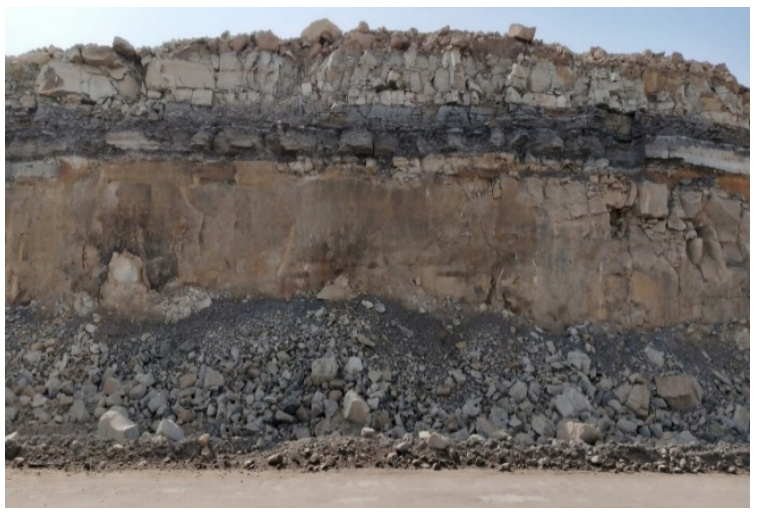

Fig. 4. The sketch diagrams of rock layering

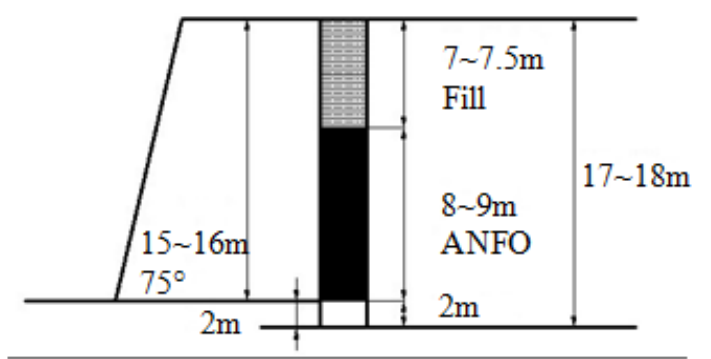

Fig. 5. Loading structure

To avoid the influence of various rock states on the test results, two blasting tests on two varied delay time combinations are conducted simultaneously in the blasting area. The blast-hole location in the blasting area and the blasting network design are shown in Fig. 6. The two delay time combinations of $18 \mathrm{~ms}-100 \mathrm{~ms}$ and $28 \mathrm{~ms}-100 \mathrm{~ms}$ are connected in parallel to the mainzhlaster through the bridging connection. TRms, the unified blasting effect of different delay time combinations in the blasting area is achieved.

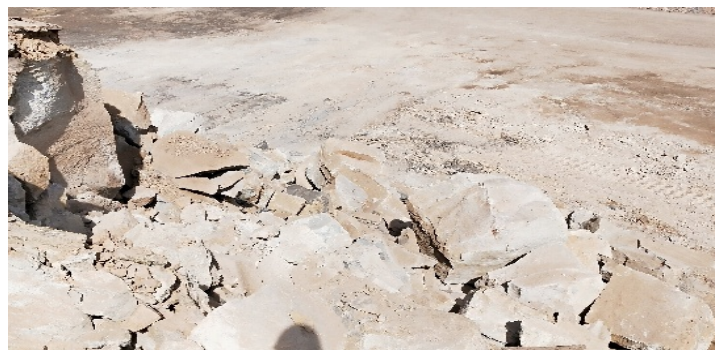

(a) $18 \mathrm{~ms}-100 \mathrm{~ms}$

Fig. 7. Configuration of the front of the reactor

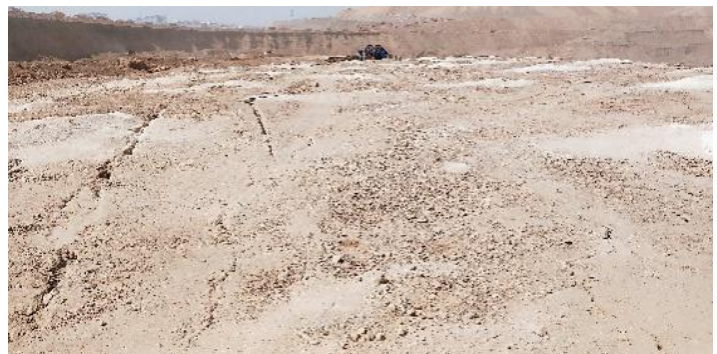

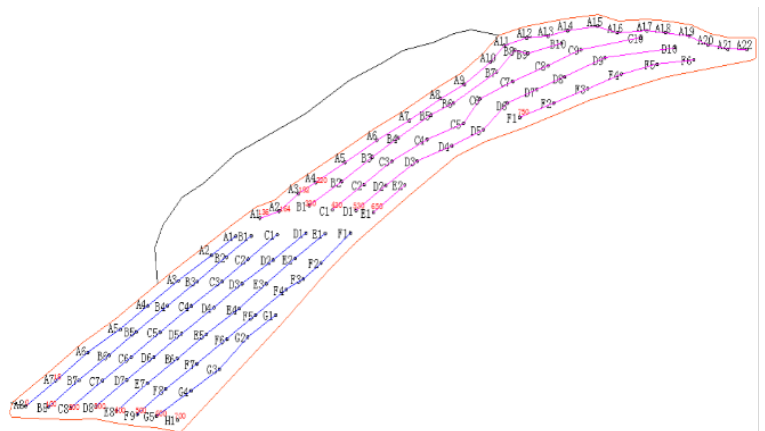

Fig. 6. The blast-hole location in the blasting area and the blasting network design

\subsection{Application of evaluation model of entropy-weight method}

From the on-site observation, no harmful blasting effect such as piercing and stone-flying in the denotation process has occurred. Meanwhile, it is measured that the combined maximum vibration speed is $80.1 \mathrm{~mm} / \mathrm{s}$ and the noise is less than $50 \mathrm{~dB}$, which has little influence on the nearby slope and the bench in the nearby blasting area.

The pre-blasting impulse of $28 \mathrm{~ms}-100 \mathrm{~ms}$ delay time combination for holes is significantly more than that of 18 ms-100ms delay time combination. Through the observation of the broken seam on bench-top rock mass and the rear collapse, it is found that the rock mass in the blasting area is entirely broken. There are a few holing seams on rock surface for the delay time combination of $17 \mathrm{~ms}-100 \mathrm{~ms}$. There are 8 holing seams between holes. There are few seams on rock mass between rows. Thus, the overall blasting effect is poor. For the delay time combination of $28 \mathrm{~ms}-100$ $\mathrm{ms}$, it is found that there are many holing seams between holes and rows. There are roughly 20 holing seams. Hence, it is indicated that the rock mass is fully broken. There are obvious collapse ditches in the back row. It shows that the blasting effect is fairly good.

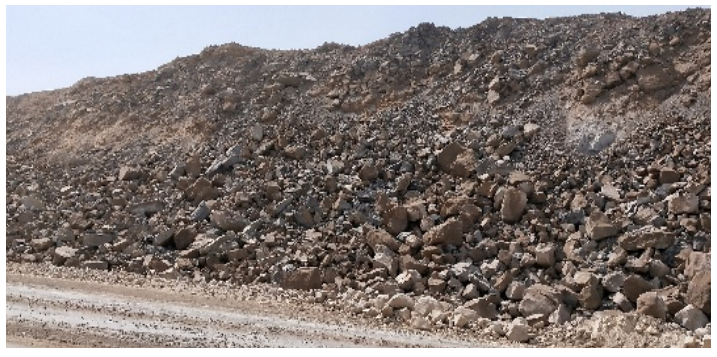

(b) $28 \mathrm{~ms}-100 \mathrm{~ms}$

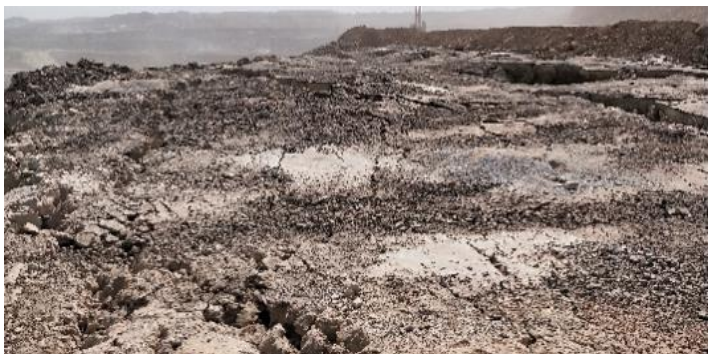


(a) $18 \mathrm{~ms}-100 \mathrm{~ms}$

Fig. 8. Fracture morphology of rock mass at the top of the bench

Through the continuous observation on the shovel loading process and the on-site statistics, it is found that there are 34 unqualified large blocks with a volume of $780.11 \mathrm{~m} 3$. The large block rate is $0.52 \%$. The location producing large blocks is at the position where the delay time combination of $17 \mathrm{~ms}$ and $100 \mathrm{~ms}$ between holes is tested. After the shovel loading, no foundation phenomenon has been found.

\section{Conclusions}

A method that combines numerical simulation and field testing was used to explore the applicable delay time for blasting in an open-pit mine under special geological conditions, where the horizontal layering is developed and the mechanical properties of rocks vary greatly. A finite element model of multilayer rock was established, and different delay times were calculated to improve the blasting effect. The evaluation model of the entropy weight method was used for analysis. The following conclusions were obtained.

(1) On the basis of the simulation results for large amounts of data and the comprehensive consideration of special geological conditions, the ratio of the maximum tangential stress of the surrounding rock to the uniaxial compressive strength of the rock and the ratio of the uniaxial compressive strength of the rock to its tensile strength were selected as evaluation indicators.

(2) The maximum effective stress in three sections was analyzed in line with the evaluation model of the entropy weight method. The weight coefficient of each index was determined with entropy information theory, and a rock damage model was established. Almost $31 \%$ of the evaluation results were medium or above. In particular, the results of $18 \mathrm{~ms}$ between holes and $100 \mathrm{~ms}$ between rows (b) $28 \mathrm{~ms}-100 \mathrm{~ms}$

were good, but the results of $28 \mathrm{~ms}$ between holes and 100 ms between rows were even better.

(3) The digital detonators in the same blasting area were applied to conduct the on-site tests. Two delay time combinations were tested. Simultaneous denotation was performed by the bridging connection. The delay time combination of 28 and $100 \mathrm{~ms}$ achieved a good result in the test and avoided the interference of various geological conditions on the blasting effects. No root phenomenon was found after shovel loading was completed.

(4) The blasting effect of the selected delay time combination was remarkably enhanced, the boulder frequency was low, and the vibration caused by blasting was reduced by $30 \%$. We conclude that in special geological conditions where the mechanical properties of rocks are different, the evaluation model of the entropy weight method presents significant advantages in the precise selection of delay time for fine blasting.

In this study, field experiments and theoretical methods were combined to provide a new understanding of the evaluation model of the entropy weight method in the industrial application of digital electronic detonators. The developed model is simplified and approximates the situation in actual field practice. It can provide a reference for the improvement of the economic benefits of millisecond blasting. In future studies, the parameters and delay time of millisecond blasting under different geological conditions can be incorporated into this model and modified to make the selection of delay time more accurate than it is at present.

\section{Acknowledgements}

This work was supported by Heidaigou Open Cast Coal Mine, Shenhua Group Zhungeer Energy CO., LTD.

This is an Open Access article distributed under the terms of the Creative Commons Attribution License

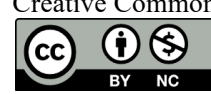

\section{References}

1. Zhang, X. H., Lu, W. Q., "Study and application of loose blasting technology with large-denssity coffienct for layered rock mass". Mining Research and Development, 39(12), 2019, pp.136-139.

2. Shao, H., Zhou, D. P., Zhou, Y. H., Xie, H. Q., "Dynamic analysis of nearly horizontal rock slopes with vertical cracks". China Civil Engineering Journal, 2006, pp.94-98.

3. Gong, M., Shi, C. F., Wu, X. D., "Delay time of electronic detonators based on superposition and frequency spectral analysis". Journal of Vibration and Shock, 38(15), 2019, pp.134-141.

4. Wang, G. S., Li, C. H., Hu, S. L., Feng, C., Li, S. H., "A study of time-and spatial-attenuation of stress wave amplitude in rock mass". Rock and Soil Mechanics, 31(11), 2010, pp.3487-3492.

5. Xu, B. S., Zhang, W. Z., Shi, W. H., "Experimental study of parameters of tunneling blasting in jointed layered rock mass". Journal of China University of Mining \& Technology, 48(06), 2019, pp.1248-1255.

6. Chen, H., Shi, X. Z., Guan, W. M., "Experimental study on blasting charge structure of layered rock mass". Journal of Xinjiang University(Natural Science Edition), 36(03), 2019, pp.361-368.

7. Chen, S. H., Yan, Y. F., Qi, G. F., "Analysis of influence factors of interference vibration reduction of millisecond blasting". Rock and Soil Mechanics, 32(10), 2011, pp.3003-3008.
8. Li, X. L., Luo, H. H., Hu, H., Zhang, S. T., "High bench castblasting effects influenced by delay time". Transactions of Beijing Institute of Technology, 38(06), 2018, pp.579-584.

9. Ye, H. W., Tang, K., Wan, T., Wang, C., "Optimization ot time sequence controlled pre-splitting blasting parameters and its application". Explosion and Shock Waves, 37(03), 2017, pp.502509.

10. Hu, C. H., Zhang, Z. C., "Study on Optimization of deep hole bench loose blasting parameters in Heidaigou open pit coal mine". Coal engineering, 50(3), 2018, pp. 22-26.

11. Xu, H. T., Lu, W. B., Zhou, X. H., "Equivalent application method of blasting load in dynamic finite element simulation of blasting vibration field". Journal of Wuhan University (Engineering Edition), 41(1), 2008, pp.67-71.

12. Song, R., "Application of waste mineral oil in ANFO explosive". Blasting equipment, 45(3), 2016, pp.51-54.

13. Liang, R., Yu, R. L., Zhou, W. H., Huang, X. B., Wang, J. Y., Xiong, Z. Y., "Application of air interval charge blasting model in room stoping". Gold science and technology, 27(03), 2019, pp.358367. 
Yin Zuoming, Wang Desheng, Zhang Xinghai, Wang Xuguang and Dang Zhiheng/

Journal of Engineering Science and Technology Review 13 (5) (2020)90 - 97

14. Zhang, Z. C., Xiong, W., Gui, M. Q., "On the selection of time interval of hole by hole initiation technology". Blasting, 28(02), 2011, pp.45-48.

15. Hajibagherpour, A. R., Mansouri, H., Bahaaddini, M., "Numerical modeling of the fractured zones around a blasthole". Computers and Geotechnics, 123, 2020, pp.103535.

16. Knock, C., Davies, N., "Blast waves from cylindrical charges". Shock Waves, 23(4), 2013, pp.337-343.

17. Yang, R. S. , Ding, C., Yang, L., et al., "Visualizing the blastinduced stress wave and blasting gas action effects using digital image correlation”. International Journal of Rock Mechanics and Mining Sciences, 112, 2018, pp.47-54.

18. Li, Q., Wang, H, J., Yang, R. S., "Experimental investigation on fracture process of multi-hole bench blasting". Journal of china coal society, 2005, pp.34-37.

19. Yang, R., Ding, C., Yang, L., et al., "Study of decoupled charge blasting based on high- -speed digital image correlation method". Tunnelling Underground Space Technol, 2019, pp.51-59.

20. Zhu, Z., "Numerical prediction of crater blasting and bench blasting". International Journal of Rock Mechanics and Mining Sciences, 46(6), 2009, pp.1088-1096.

21. Qing, L., Yang, G., Wen, L. X., et al., "Investigation on the dynamic fracture property of oblique open-joints under bunch-hole explosion". Journal of Vibration and Shock, 38(06), 2019, pp.151158 .

22. Yang, G., Qing, L., Wen, L. X., et al., "Dynamic fracture process of a pre-crack under linear charge explosion". Rock Soil Mechanics, 39(10), 2018, pp.3882-3890.

23. Zhou, J., Zhang, L. Q., Hu, R. L., Wang, X. L., "Study of rules of stress waves propagation under various attitudes of large-scale fractures". Chinese Journal of Rock Mechanics and Engineering, 30(04), 2011, pp.769-780.

24. Zareifard, M. R., "A new semi-numerical method for elastoplastic analysis of a circular tunnel excavated in a Hoek-Brown strainsoftening rock mass considering the blast-induced damaged zone". Computers and Geotechnics, 2020, pp.103476.

25. Wang, J., LI, E. B., Tan, Y. H., You, Y. C., "Comparative experimental study on dynamic mechanical properties of bedded salt rock and mudstone interbed".Chinese Journal of Rock Mechanics and Engineering, 36(12), 2017, pp.3002-3011.

26. Shi, X. P., Xie, L. K., Wu, C. P., Ye, G. X., "Study on the reasonable intervals of millisecond delay blasting". Nonferrous Metals(Mining Section), 2015, pp.85-88.
27. Chen, H., Shi, X. Z., Guan, W. M., "experimental study on blasting charge structure of layered rock mass". Journal of Xinjiang University(Natural Science Edition), 2019, pp.361-368.

28. Song, Q. J., Li, H. B., Li, J. R., Yao, W. S., Yang, F . W., Wang, M., "Influence of stratification on attenuation law of blasting vibration". Chinese Journal of Rock Mechanics and Engineering, 31(10), 2012, pp.2103-2108.

29. Raina, A. K., Murthy, V. M. S. R., Soni, A. K., "Estimating flyrock distance in bench blasting through blast induced pressure measurements in rock". International Journal of Rock Mechanics and Mining Sciences, 2015, pp. 209-216.

30. Singh, B. K., Mondal, D., Shahid, M., Saxena, A., Roy, P. N. S. "Application of digital image analysis for monitoring the behavior of factors that control the rock fragmentation in opencast bench blasting: A case study conducted over four opencast coal mines of the Talcher Coalfields, India". Journal of Sustainable Mining, 2019, pp.247-256.

31. Zhong, D. W., He, L., Cao, P., Zhang, K., "Analysis of blasting vibration duration and optimizing of delayed time interval for millisecond blasting". Explosion and Shock Waves, 36(05), 2016, pp.703-709.

32. Iwano, K., Hashiba, K., Nagae, J., Fukui, K., "Reduction of tunnel blasting induced ground vibrations using advanced electronic detonators". Tunnelling and Underground Space Technology, 105, 2020. pp. 103556.

33. Azizabadi, H. R. M., Mansouri, H., and Fouche, O., "Coupling of two methods, waveform superposition and numerical, to model blast vibration effect on slope stability in jointed rock masses". Computers and Geotechnics, 2014, pp.42-49.

34. Torres, V. F. N., Silveira, L. G. C., Lopes, P. F. T., Lima, H. M., "Assessing and controlling of bench blasting-induced vibrations to minimize impacts to a neighboring community". Journal of Cleaner Production, 2018, pp.514-524.

35. Xue, J. G., Zhou, J., Shi, X. Z., Wang, H. Y., Hu, H. Y., "Assessment of classification for rock mass blastability based on entropy coefficient of attribute recognition model". Journal of Central South University(Science and Technology), 41(01), 2010, pp.251-256.

36. Wang, Y. C., Shang, Y. Q., Sun, H. Y., Yan, X. S., "Research and application of rockburst intensity prediction model based on entropy coefficient and ideal point method". Journal of china coal society, 2010, pp.218-221. 